\title{
Effect of $\mathbf{P}$ on nodule formation and $\mathbf{N}$ fixation in bean
}

\author{
Saber KouAs, Nahla LABIDI, Ahmed DeBeZ, Chedly ABDELly* \\ Laboratoire d'Adaptation des Plantes aux Stress Abiotiques, INRST, BP 95, 2050, Hammam-Lif, Tunisia
}

(Accepted 25 April 2005)

\begin{abstract}
The present study compares the demands for $\mathrm{P}$ of the initial nodule formation, and of the later growth and functioning of the nodulated root system in two inoculated lines of common bean (Coco blanc and BAT477). After germination and inoculation, seedlings were divided into two lots. One lot was grown under constant P supply, either 15 (low) or 250 (high) $\mu \mathrm{M} \mathrm{P}$, corresponding to provision of 120 and $2000 \mu \mathrm{mol} P$, respectively. In the second, seedlings were cultivated on the same medium supplied with $15 \mu \mathrm{M}$ P for 24 days after germination, and then with 60 or $250 \mu \mathrm{M}$ (total provision of P: respectively, 390 and $1530 \mu \mathrm{mol}$ ). Nodule number and biomass were significantly diminished by the low P $(120 \mu \mathrm{mol})$ treatment, as compared with the other treatments. However, the intrinsic characteristics of the nodules (individual biomass and size, $\mathrm{P}$ concentration and efficiency of $\mathrm{N}$ fixation) did not depend on $\mathrm{P}$ availability. Although the bean line BAT477 was distinguished from the Coco blanc line through higher nodule number, size, biomass, and nitrogen fixation, both lines displayed analogous responses to $\mathrm{P}$ availability.
\end{abstract}

Phaseolus vulgaris / P availability / nodulation / P allocation / symbiotic nitrogen fixation

\section{INTRODUCTION}

In legumes, phosphorus deficiency specially affects symbiotic fixation of $\mathrm{N}_{2}$ by limiting growth and survival of rhizobia (O'Hara et al., 1988), nodule formation (Drevon and Hartwig, 1997) and functioning (Tang et al., 2001a), and host plant growth (Tsvetkova and Georgiev, 2003). In addition, phosphorus deficiency has previously been reported to decrease nodule mass more than host growth in soybean (Drevon and Hartwig, 1997). Reports on P requirements for nodule formation and functioning are controversial: phosphorus deficiency may increase, decrease or not affect the nodule number per unit of shoot mass (Drevon and Hartwig, 1997; Gunawardena et al., 1992; Pereira and Bliss, 1989; Ribet and Drevon, 1995; Tang et al., 2001a; Vadez et al., 1996), as well as the specific nitrogenase activity and/or the amount of $\mathrm{N}$ fixed per nodule mass (Tang et al., 2001b; Vadez et al., 1996, 1997). Differences in the response of nodule formation and functioning to $\mathrm{P}$ deficiency appear thus to be related to legume species, line and experimental conditions. Additionally, the response of plants to $\mathrm{P}$ deficiency might depend on the duration and the severity of the stress. At early development stages, both P-efficient and P-inefficient common bean lines require relatively low $\mathrm{P}$ for optimal nodule initiation (Tang et al., 2001b). However, at later stages and in nodulated plants subjected to severe $\mathrm{P}$ deficiency, the further growth of already established nodules seemed to decrease (Valverde et al., 2002) or to be fully inhibited (Almeida et al., 2000).
The objective of the present study was to compare the demands for $\mathrm{P}$ of the initial nodule formation, and of the later growth and functioning of the nodulated root system. The plants were grown either in P-limiting or in P-sufficient conditions from sowing to flowering. In parallel treatments, P-limiting conditions were applied only during the initiation and early development of nodules, and then the plants were returned to $\mathrm{P}$ sufficiency conditions. Two inoculated lines of common bean (Phaseolus vulgaris L.) were used.

\section{MATERIALS AND METHODS}

\subsection{Plant material and growth conditions}

Two lines of common bean were chosen: Coco blanc, commonly cultivated all around the Mediterranean sea, and BAT477, which is considered as more tolerant to a variety of abiotic constraints (Saadallah et al., 2001; Tang et al., 2001b). After germination and inoculation with Rhizobium tropici CIAT 899 (originating from the International Center of Tropical Agriculture, Colombia), seedlings were hydroaeroponically (Tang et al., 2001b; Vadez and Drevon, 2001) grown in a glasshouse under natural light. Each pot, containing 1 seedling, was filled with 1 liter of the following nutrient solution: $\mathrm{MgSO}_{4}$ $\left(120.5 \mathrm{mg} \mathrm{L}^{-1}\right), \mathrm{K}_{2} \mathrm{SO}_{4}\left(122 \mathrm{mg} \mathrm{L}^{-1}\right), \mathrm{CaCl}_{2}\left(180 \mathrm{mg} \mathrm{L}^{-1}\right)$, $\mathrm{H}_{3} \mathrm{BO}_{3}\left(0.25 \mathrm{mg} \mathrm{L}^{-1}\right), \mathrm{MnSO}_{4}\left(0.6 \mathrm{mg} \mathrm{L}^{-1}\right), \mathrm{ZnSO}_{4}\left(0.16 \mathrm{mg} \mathrm{L}^{-1}\right)$,

* Corresponding author: chedly.abdelly@inrst.rnrt.tn 
Table I. Different P levels used during the culture of two common bean lines (Coco blanc and BAT477). DAG: days after germination.

\begin{tabular}{lccc}
\hline Treatments & \multicolumn{3}{c}{ P provision per plant } \\
\cline { 2 - 4 } & $\begin{array}{c}\text { From 5 to 24 DAG } \\
\mu \text { mol week }^{-1}\end{array}$ & $\begin{array}{c}\text { From 24 to 62 DAG } \\
\mu \text { mol week }^{-1}\end{array}$ & $\begin{array}{c}\text { Total (62 days) } \\
\mu \text { mol }\end{array}$ \\
\hline low-low & 15 & 15 & 120 \\
low-medium & 15 & 60 & 390 \\
low-high & 15 & 250 & 1530 \\
high-high & 250 & 250 & 2000 \\
\hline
\end{tabular}

$\mathrm{CuSO}_{4}\left(0.16 \mathrm{mg} \mathrm{L}^{-1}\right), \mathrm{CoCl}_{2}\left(0.016 \mathrm{mg} \mathrm{L}^{-1}\right)$ and $\mathrm{Na}_{6} \mathrm{Mo}_{7} \mathrm{O}_{24}$ $\left(0.14 \mathrm{mg} \mathrm{L}^{-1}\right)$. The nutrient solution was renewed weekly, the $\mathrm{pH}$ was maintained near neutrality with $\mathrm{CaCO}_{3}\left(1 \mathrm{~g} \mathrm{~L}^{-1}\right)$, and the solution was constantly aerated at a flow of $400 \mathrm{~mL} \mathrm{~min}^{-1}$.

\subsection{Experimental design and $P$ treatments}

Three levels (low, medium and high) of P supply were used, respectively, corresponding to 15,60 and $250 \mu \mathrm{M} \mathrm{P}$, as $\mathrm{KH}_{2} \mathrm{PO}_{4}$, in the medium. They provided each plant with, respectively, 15, 60 and $250 \mu \mathrm{mol} \mathrm{P}$. The nutrient solutions were supplemented with $\mathrm{KCl}$ to equalize $\mathrm{K}$ supply over these $P$ treatments. After 5 days of germination on agar imbibed with water, seedlings were transferred for 2 weeks to a pretreatment solution with either low or high P level. 24 days after germination, the plants were transferred to treatment solution with low, medium or high P level, as described in Table I. Final harvest occurred 6 weeks later (61 days after germination). Urea $(2 \mathrm{mM} \mathrm{N})$ was added at 24 days after germination. Thereafter, the plants did not receive any external source of $\mathrm{N}$.

\subsection{Measured parameters}

At the beginning of the flowering stage (52 days after germination), three plants from each treatment were used for the assessment of nodule nitrogenase activity, estimated by the acetylene reduction assay (Hardy et al., 1968). Ten other plants were harvested 61 days after germination, and separated into roots, shoots and nodules. Samples were then dried at $60{ }^{\circ} \mathrm{C}$ to constant dry weight. Dried nodules were counted, separated into two size classes using wire-mesh sieves (diameter $<$ or $>$ $0.5 \mathrm{~mm}$ ) and ground. A 25-mg dry weight nodule sample from each plant was digested in concentrated $\mathrm{HNO}_{3}$. Phosphate was assayed using the vanado-molybdate method (Fleury and Leclerc, 1943).

For $\mathrm{N}$ determination, the sample was digested in hot concentrated $\mathrm{H}_{2} \mathrm{SO}_{4}$, as described by Kjeldahl. The symbiotic nitrogen fixation was estimated as the difference between $\mathrm{N}$ quantities (mmol plant ${ }^{-1}$ ) at 61 and 24 days after germination.

\subsection{Statistical analysis}

Analysis of variance (ANOVA) was used for the statistical analysis of data. Mean separation procedures were carried out using the multiple range tests with Fisher's least significant difference $(\mathrm{LSD})$ procedure $(P<0.05)$.

\section{RESULTS AND DISCUSSION}

\subsection{Plant growth and nodule development}

As compared with the other treatments, the low-low treatment restricted the whole plant growth of the bean line Coco blanc, but not that of the BAT477 line (Tab. II). Shoots rather than roots reflected this response to $\mathrm{P}$ shortage. An increase in the root/shoot ratio is known to frequently occur in P-starved plants (Tang et al., 2001b). The nodule biomass (Fig. 1) represented 4 to $8 \%$ of whole plant biomass when $\mathrm{P}$ was not limiting (not shown). These values are comparable with those published for common bean (Saadallah et al., 2001; Vadez and Drevon, 2001).

Table II. Whole plant, root, and individual nodule biomass and plant to nodule biomass ratio of two common bean lines (Coco blanc and BAT477) cultivated with low, medium or high P levels, as described in Table I. Data are the means \pm SE of 10 replicates. Mean values followed by the same letter are not significantly different at $P<0.05$.

\begin{tabular}{|c|c|c|c|c|c|}
\hline & & \multicolumn{4}{|c|}{ Treatments } \\
\hline & & low-low & high-high & low-medium & low-high \\
\hline \multirow[t]{2}{*}{ Plant biomass (g dry weight) } & Coco blanc & $1.8 \pm 0.6 a$ & $5.0 \pm 1.1 \mathrm{cbd}$ & $4.3 \pm 0.4 \mathrm{cb}$ & $4.17 \pm 0.4 \mathrm{cb}$ \\
\hline & BAT477 & $4.3 \pm 0.4 \mathrm{cb}$ & $3.9 \pm 0.9 b$ & $5.1 \pm 0.6 \mathrm{~cd}$ & $5.4 \pm 0.9 \mathrm{~d}$ \\
\hline \multirow[t]{2}{*}{ Root biomass (g dry weight) } & Coco blanc & $1.1 \pm 0.1 b$ & $0.9 \pm 0.3 \mathrm{ab}$ & $1.1 \pm 0.1 b$ & $1.1 \pm 0.1 b$ \\
\hline & BAT477 & $1.0 \pm 0.1 \mathrm{ab}$ & $0.8 \pm 0.2 \mathrm{a}$ & $1.0 \pm 0.1 \mathrm{ab}$ & $0.9 \pm 0.1 \mathrm{ab}$ \\
\hline \multirow{2}{*}{$\begin{array}{l}\text { Mean biomass of individual } \\
\text { nodules (mg dry weight) }\end{array}$} & Coco blanc & $1.23 \pm 0.58 \mathrm{a}$ & $1.27 \pm 0.35 \mathrm{ab}$ & $1.42 \pm 0.28 \mathrm{ab}$ & $1.95 \pm 0.56 b$ \\
\hline & BAT477 & $1.14 \pm 0.17 \mathrm{a}$ & $1.12 \pm 0.46 \mathrm{a}$ & $0.91 \pm 0.20 \mathrm{a}$ & $1.34 \pm 0.30 \mathrm{ab}$ \\
\hline \multirow[t]{2}{*}{ Plant biomass / Nodule biomass } & Coco blanc & $22.0 \pm 6.9 \mathrm{ab}$ & $18.9 \pm 5.6 \mathrm{ab}$ & $13.9 \pm 2.6 \mathrm{a}$ & $21.5 \pm 9.4 \mathrm{ab}$ \\
\hline & BAT477 & $32.8 \pm 7.4 b$ & $31.4 \pm 15.4 b$ & $32.9 \pm 16.0 \mathrm{~b}$ & $24.2 \pm 7.1 \mathrm{ab}$ \\
\hline
\end{tabular}




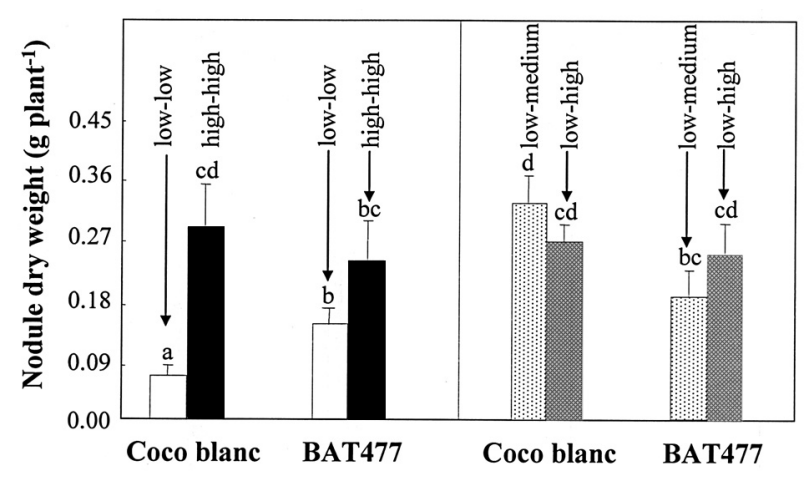

Figure 1. Effect of phosphorus availability on nodule biomass $\left(\right.$ g plant $^{-1}$ ) of two common bean lines (Coco blanc and BAT477). Plants were cultivated with low, medium or high P levels, as described in Table I. Data are the means \pm SE of 10 replicates. Mean values followed by the same letter are not significantly different at $P<0.05$.
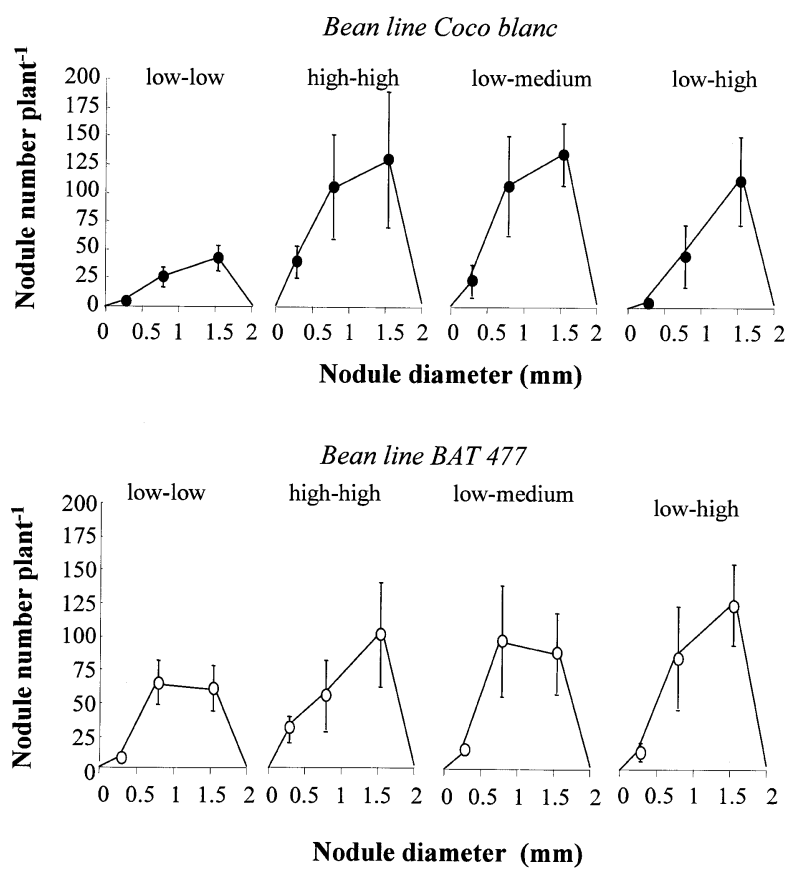

Figure 2. Effect of phosphorus availability on nodule size (mm) distribution of two common bean lines (Coco blanc and BAT477). Plants were cultivated with low, medium or high P levels, as described in Table I. Data are the means \pm SE of 10 replicates.

The lowest numbers of nodules per plant were recorded when $\mathrm{P}$ shortage persisted during the whole plant cycle (lowlow treatments) (Fig. 2). Treatments with P shortage at the early development stage of the plants followed by late application of 60 or $250 \mu \mathrm{M}$ P (low-medium and low-high) led to nodule production similar to that of the high-high treatment (Fig. 1). These results suggest that early restriction of nodule formation by
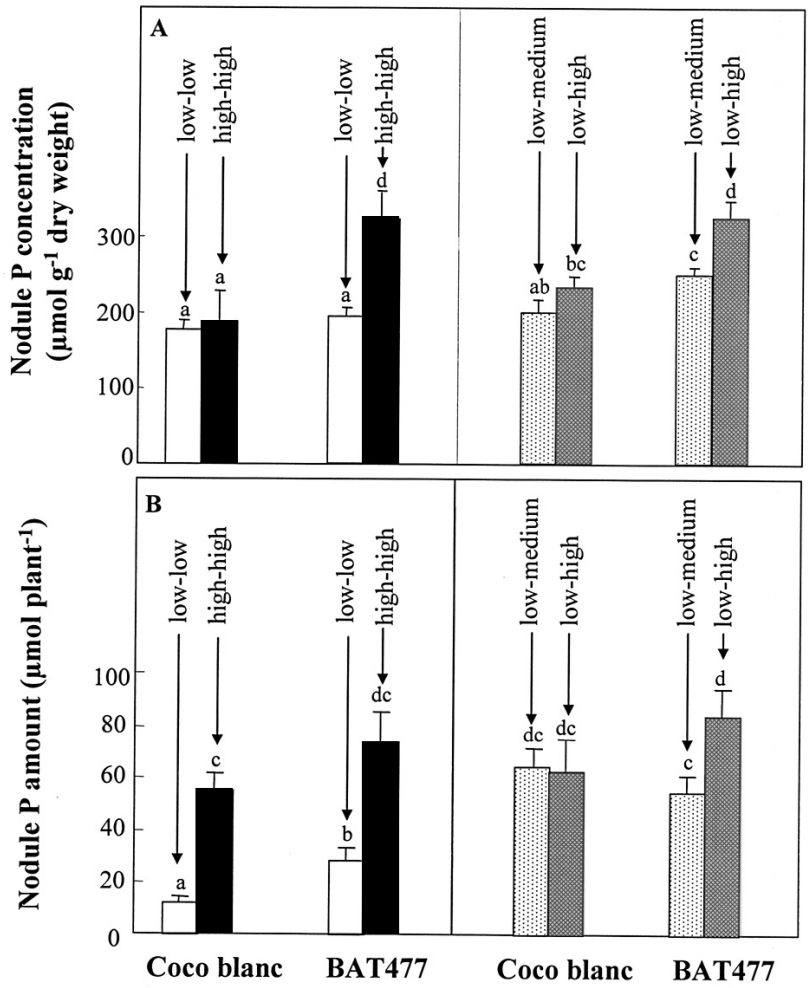

Figure 3. Effect of phosphorus availability on nodule $P$ status of two common bean lines (Coco blanc and BAT477). Plants were cultivated with low, medium or high P levels, as described in Table I. (A) Nodule $\mathrm{P}$ concentration ( $\mu \mathrm{mol} \mathrm{g}{ }^{-1}$ dry weight). (B) Nodule $\mathrm{P}$ amount $\left(\mu\right.$ mol plant $\left.{ }^{-1}\right)$. Data are the means \pm SE of 10 replicates. Mean values followed by the same letter are not significantly different at $P<0.05$.

insufficient $\mathrm{P}$ provision was compensated by late nodule initiation, after returning the plants to P-sufficient conditions (lowmedium and low-high treatments).

For both lines, the mean biomass (Tab. II) and size distribution (Fig. 2) of the individual nodules did not significantly differ between the treatments. For the nodule size distribution, the modal class was that of the larger size value (diameter larger than $1 \mathrm{~mm}$ ) in all treatments, including low-low. Thus, nodule growth was not restricted by $\mathrm{P}$ shortage, even when it lasted during the whole plant cycle. Only the nodule number was dependent on P supply.

The ratio of plant biomass to nodule biomass estimates the intrinsic capacity of nodules to support plant growth, i.e. the symbiosis efficiency. This parameter was consistently higher in the bean line BAT477 than in the Coco blanc line, but for both lines, there was no significant difference between treatments (Tab. II).

\subsection{Nodule $P$ status}

$\mathrm{P}$ concentration in nodules was much less sensitive to $\mathrm{P}$ shortage (low-low treatment) than the amount of P accumulated in nodules (Fig. 3). For instance (Coco blanc), P concentration 


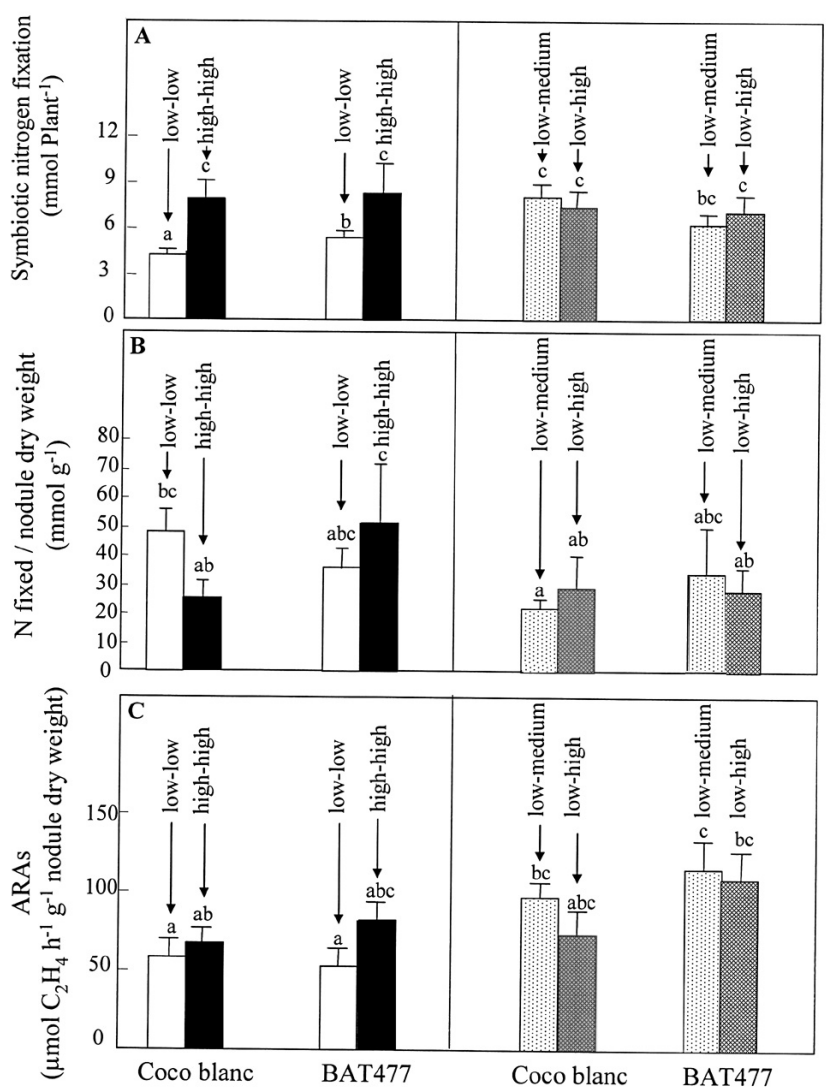

Figure 4. Effect of the P supply mode on symbiotic nitrogen fixation of two common bean lines (Coco blanc and BAT477). Plants were cultivated with low, medium or high $\mathrm{P}$ levels, as described in Table I. (A) Nitrogen amount $\left(\mathrm{mmol}^{\mathrm{p}} \mathrm{plant}^{-1}\right)$. (B) $\mathrm{N}$ fixed / nodule dry weight $\left(\mathrm{mmol} \mathrm{g}^{-1}\right)$. (C) Specific nitrogenase activity, ARAs $\left(\mu \mathrm{mol} \mathrm{C}{ }_{2} \mathrm{H}_{4} \mathrm{~h}^{-1} \mathrm{~g}^{-1}\right.$ nodule DW). Data are the means \pm SE of 10 replicates. Mean values followed by the same letter are not significantly different at $P<0.05$.

in nodules was the same for the low-low and high-high treatments (Fig. 3A). On the contrary, the amount of $\mathrm{P}$ associated with the nodule fraction of low-low plants was ca. $20 \%$ that of high-high plants (Fig. 3B). In the bean line BAT477, the P concentration in low-low nodules was $60 \%$ that of high-high nodules, while $\mathrm{P}$ amount was only $39 \%$. Thus, restricting $\mathrm{P}$ availability limited nodule biosynthesis more than nodule enrichment in P. This effect was more marked in the bean line Coco blanc than in the BAT477 line.

\subsection{Symbiotic nitrogen fixation}

For both lines Coco blanc and BAT477, the symbiotic nitrogen fixation capacity (mmol $\mathrm{N}_{\text {plant }}{ }^{-1}$ ) was lower in the plants submitted to continuous $\mathrm{P}$ deficiency (low-low) than in plants with early (high-high) or late (low-medium, low-high) sufficient $\mathrm{P}$ provision (Fig. 4A). This trend was no longer apparent when the amounts of fixed $\mathrm{N}$ were expressed on a nodule mass basis (Fig. 4B), suggesting that early $\mathrm{P}$ deficiency did not restrict nodule functioning. Indeed, acetylene reduction activity estimation did not discriminate between treatments with early vs. late $\mathrm{P}$ provision (Fig. 4C). The acetylene reduction activity assay in a closed system may underestimate the nitrogenase activity, owing to acetylene-induced inhibition of this enzyme. However, this assay is useful for comparative purposes (Minchin et al., 1983). Since our above conclusion relies on relative acetylene reduction activity values, we hypothesize that it is not affected by a possible nitrogenase inhibition.

\section{CONCLUSION}

Our results indicate that, when $\mathrm{P}$ is limiting for whole plant growth, the number of nodules is severely restricted, resulting in lowered symbiotic nitrogen fixation capacity for the whole plant. However, return to normal $P$ nutrition permits a compensatory nodule initiation and growth, so that there may be no after-effect of the $\mathrm{P}$ shortage period. Nodule growth, as distinguished from nodule initiation, is not restricted by $\mathrm{P}$ shortage. Even when the plant growth is limited by $\mathrm{P}$ availability during the whole cycle, the few nodules formed present normal growth. Priority seems to be given to preserving the $\mathrm{P}$ nutrition of the nodules. The functional characteristics of the nodules are also independent of P supply: neither the symbiosis efficiency nor the estimated specific nitrogenase activity are significantly diminished by $\mathrm{P}$ restriction. In conclusion, under our experimental conditions characterized by relative low growth activity of the plant, nodule initiation but not nodule growth and functioning depends on sufficient $\mathrm{P}$ supply in common bean. Perhaps there is some regulation of nodule initiation which adjusts the number of nodules to $\mathrm{P}$ availability, so that optimal nodule performance is maintained.

Acknowledgements: We are deeply grateful to Pr. Claude GRIGNON (B and PMP, Agro-M INRA, Montpellier, France) and Dr. Steve BEEBE (CIAT, Cali, Colombia) for improving the English of the manuscript.

\section{REFERENCES}

Almeida J.P.F., Hartwig U.A., Frehner M., Nosenberger J., Luscher A. (2000) Evidence that $P$ deficiency induces feed back regulation of symbiotic $\mathrm{N}_{2}$ fixation in white clover (Trifolium repens L.), J. Exp. Bot. 51, 1289-1297.

Drevon J.J., Hartwig U.A. (1997) Phosphorus deficiency increases the argon-induced decline of nodule nitrogenase activity in soy bean and alfalfa, Planta 201, 463-469.

Fleury P., Leclerc M. (1943) La méthode nitro-vanadomolybdique de Misson pour le dosage colorimétrique du phosphore. Son intérêt en Biochimie, Bull. Chim. Biol. 25, 201-205.

Gunawardena S.F.B.N., Danso S.K.A., Zapata F. (1992) Phosphorus requirement and nitrogen accumulation by three mungbean (Vigna radiate (L.) Welzek) cultivars, Plant Soil 147, 267-274.

Hardy W.F.R., Holsten R., Jackson E., Burns E. (1968) The acetyleneethylene assay for nitrogen fixation: lab and field assay for nitrogen evaluation, Plant Physiol. 43, 1185-1207.

Minchin F.R., Witty J.F., Sheehy J.E., Muller M. (1983) A major error in the acetylene reduction assay: decreases in nodular nitrogenase activity under assay conditions, J. Exp. Bot. 34, 641-649. 
O'Hara G.W., Boonkered N., Dilworth M.J. (1988) Mineral constraints to nitrogen fixation, Plant Soil 108, 93-110.

Pereira P.A.A., Bliss F.A. (1989) Selection of common bean (Phaseolus vulgaris $\mathrm{L}$.) for $\mathrm{N}_{2}$ fixation at different levels of available phosphorus under field and environmentally-controlled conditions, Plant Soil 115, 75-82.

Ribet J., Drevon J.J. (1995) Phosphorus deficiency Increases the acetylene-induced decline in nitrogenase activity in soybean (Glycine $\max$ L. Merr.), J. Exp. Bot. 46, 1479-1486.

Saadallah K., Drevon J.J., Abdelly C. (2001) Nodulation et croissance nodulaire chez le haricot (Phaseolus vulgaris) sous contrainte saline, Agronomie 21, 627-634.

Tang C., Hinsinger P., Drevon J.J., Jaillard B. (2001a) Phosphorus deficiency impairs early nodule functioning and enhances proton release in roots of Medicago truncatula L., Ann. Bot. 88, 131-138.

Tang C., Hinsinger P., Jaillard B., Rengel Z., Drevon J.J. (2001b) Effect of phosphorus deficiency on the growth, symbiotic $\mathrm{N}_{2}$ fixation and proton release by two bean (Phaseolus vulgaris) genotypes, Agronomie 21, 683-689.
Tsvetkova G.E., Georgiev G.I. (2003) Effect of phosphorus nutrition on the nodulation, nitrogen fixation and nutrient-use efficiency of Bradyrhizobium japonicun soybean (Glycine max L. Merr.) symbiosis, Bulg. J. Plant Physiol. Special issue 331-335.

Vadez V., Rodier F., Payre H., Drevon J.J. (1996) Nodule permeability to $\mathrm{O}_{2}$ and nitrogenase-linked respiration in bean genotypes varying in the tolerance of $\mathrm{N}_{2}$ fixation to P deficiency, Plant Physiol. Biochem. 34, 871-878.

Vadez V., Beck D.P., Lasso J.H., Drevon J.J. (1997) Utilization of the acetylene reduction assay to screen for tolerance of symbiotic $\mathrm{N}_{2}$ fixation to limiting P nutrition in common bean, Physiol. Plant. 99, 227-232.

Vadez V., Drevon J.J. (2001) Genotypic variability in phosphorus use efficiency for symbiotic $\mathrm{N}_{2}$ fixation in common bean (Phaseolus vulgaris), Agronomie 21, 691-699.

Valverde C., Ferrari A., Wall L.G. (2002) Phosphorus and the regulation of nodulation in the actinorhizal symbiosis between Discaria trinervis (Rhamnaceae) and Frankia BCU110501, New Phytol. 153, 43-51.

To access this journal online: www.edpsciences.org 